\title{
Influence of boron doping on mechanical and tribological properties in multilayer CVD-diamond coating systems
}

\author{
SAJAD HUSSAIN DIN ${ }^{1, *}$ M A SHAH ${ }^{2}$, N A SHEIKH ${ }^{1}$, K A NAJAR $^{1}$, K RAMASUBRAMANIAN $^{3}$, \\ S BALAJI ${ }^{3}$ and M S RAMACHANDRA RAO ${ }^{3}$ \\ ${ }^{1}$ Department of Mechanical Engineering, National Institute of Technology, Srinagar 190006, India \\ ${ }^{2}$ Department of Physics, National Institute of Technology, Srinagar 190006, India \\ ${ }^{3}$ Nano Functional Materials Technology Centre, Department of Physics, Indian Institute of Technology Madras, \\ Chennai 600036, India
}

MS received 20 January 2016; accepted 20 April 2016

\begin{abstract}
Titanium alloy (Ti6Al4V) substrates were deposited with smooth multilayer coatings, by hot filament chemical vapour deposition technique. The effect of boron doping on lattice parameter, residual stresses, hardness and coefficient of friction in multilayer-diamond coating system was studied. The frictional behaviour of the coatings was studied using a ball-on-disc micro-tribometer by sliding the coated samples of titanium alloy (Ti6Al4V) substrates against alumina $\left(\mathrm{Al}_{2} \mathrm{O}_{3}\right)$ balls, and increasing normal load from 1 to $10 \mathrm{~N}$. The average friction coefficient decreased from 0.36 to 0.29 for undoped multilayer-diamond coating system and from 0.33 to 0.18 for borondoped (BD) multilayer-diamond coating system. The average indentation depths for undoped and BD multilayerdiamond coating systems were found to be equal to $\sim 58$ and $\sim 65 \mathrm{~nm}$, respectively, and their hardness values were 60 and $55 \mathrm{GPa}$, respectively.
\end{abstract}

Keywords. Boron doping; multilayer CVD-diamond coatings; nano-indentation; $\mathrm{Al}_{2} \mathrm{O}_{3}$; hardness; friction coefficient.

\section{Introduction}

Chemically vapour-deposited diamond is well known for its splendid physical and chemical properties, like wide bandgap, negative electron affinity, chemical inertness, extreme hardness, thermal conductivity and resistance to particle bombardment. It is a promising material for applications in various micro-electromechanical devices [1-5]. Nevertheless, the application of microcrystalline diamond (MCD) film is greatly limited because of the relatively low surface smoothness and the large grains. Thus, it will cost much time and work to polish MCD [6]. On the other hand, nanocrystalline diamond (NCD) or ultra-NCD film has low surface roughness and fine nano-scaled grains. Therefore, a multilayer-diamond coating system was designed to improve the mechanical and tribological properties by combining the advantages of boron-doped diamond (BDD), MCD and NCD. A transition layer was used between the MCD and NCD coatings by changing the process parameters [7-9]. Multilayered-diamond coatings show lowest average grain size and splendid adhesion strength as compared to single layered nanocrystalline coating $[10,11]$. A multilayereddiamond coating system has an advantage of prevention of enormous MCD grain growth, improves the fracture toughness and reduces the residual stresses [12-15].

\footnotetext{
*Author for correspondence (sajad_08phd12@ nitsri.net)
}

Due to high adhesion between MCD and NCD, the interfaces between two diamond layers in multilayer coating system play an important role on the mechanical behaviour [16-18]. The tribological and mechanical characteristics of ceramics, carbides and hard metals can also be increased by multilayer-diamond coatings. This may be due to the increase in adhesion between the coating and the substrate, allowing higher loads, reduction of residual thermal stresses and improving force of delamination [19-21]. Diamond can be refined by an appropriate amount of boron dopant on a single layer diamond coating. This will also reduce film residual stress, change grain size and improve quality of the coating [22-24]. The Raman spectroscopy reveals that the undoped diamond coatings show compressive stresses, while the BDD coatings show tensile stresses. The friction tests reveal that the average coefficient of friction for doped diamond coatings is lower as compared to the undoped diamond films. The surface of BDD is rougher as compared to the undoped diamond with larger grain size $[25,26]$.

In the present study, influence of boron doping on mechanical and tribological properties in multilayer CVDdiamond coating systems were studied. Smooth and adhesive undoped and BD multilayer CVD-diamond coatings (each $3 \mu \mathrm{m}$ thick) were deposited on chemically etched Ti6Al4V substrates, using hot filament chemical vapour deposition (HFCVD) technique. Each layer, i.e., MCD, TL, NCD and BDNCD is $1 \mu \mathrm{m}$ thick. These coatings were 
achieved with the architectures of Ti6Al4V/MCD-TL-NCD and Ti6Al4V/MCD-TL-BDNCD, by controlling the process parameters. Raman spectroscopy technique was used to identify the nature of top-layer, nature of residual stresses and their estimation, crystalline quality and to identify the boron content in diamond film. Systematic investigation of the relationship between applied normal load and frictional coefficient was carried out to better understand the tribological behaviour of undoped and BD multilayer-diamond coating systems. Friction characteristics were studied using ball-on-disc type linear reciprocating microtribometer, sliding against smooth alumina $\left(\mathrm{Al}_{2} \mathrm{O}_{3}\right)$ ball under dry atmospheric conditions. Nano-indentation tests were conducted using Berkovich nano-indenter and the values of hardness $(H)$ were calculated from the load-displacement data. The values of elastic modulus $(E)$ were calculated using Oliver and Pharr mathematical procedure [27].

\section{Experimental}

Ti6Al4V substrates of size $2.3 \mathrm{~cm}$ diameter and thickness $0.3 \mathrm{~cm}$, with surface roughness $(\mathrm{Ra})$ of $\sim 0.35 \mu \mathrm{m}$ were

Table 1. Experimental conditions.

\begin{tabular}{lc}
\hline Parameters & Operating conditions \\
\hline Normal load & $1,5,10 \mathrm{~N}$ \\
Sliding velocity & $8 \mathrm{~cm} \mathrm{~s}^{-1}$ \\
Relative humidity & $60( \pm 5) \%$ \\
Duration of rubbing & $20 \mathrm{~min}$ \\
Surface condition & Dry \\
Substrate & Ti6Al4V \\
Material tested & Ti6Al4V/MCD-TL-NCD and \\
& Ti6Al4V/MCD-TL-BDNCD \\
Ball material & Alumina $\left(\mathrm{Al}_{2} \mathrm{O}_{3}\right)$ \\
Diameter of ball & $6 \mathrm{~mm}$ \\
Stroke length & $5 \mathrm{~mm}$ \\
Frequency & $2 \mathrm{~Hz}$ \\
Temperature & $30 \pm 1^{\circ} \mathrm{C}$ \\
Roughness factor $(R a):$ & $\sim 0.11 \mu \mathrm{m}$ \\
NCD & $\sim 0.18 \mu \mathrm{m}$ \\
BDNCD & \\
\hline
\end{tabular}

cleaned in ethyl alcohol with ultrasonic agitation to remove the impurities from the surface. Multilayer CVD-diamond (undoped and BD) coatings were successfully deposited on these substrates, using HFCVD technique with approximate uniform thickness of $\sim 3 \mu \mathrm{m}$. The boron content is formed when trimethyl borate $\left(\mathrm{C}_{3} \mathrm{H}_{9} \mathrm{BO}_{3}\right)$ is dissolved in acetone solution and the mixed solution in the liquid container is introduced in the reactor by part of $\mathrm{H}_{2}$. Structural characteristics of these coatings were studied using grazing incidence $\mathrm{X}$-ray diffraction (XRD, PANalytical) technique with $\mathrm{CuK} \alpha$ $(\lambda=0.154 \mathrm{~nm})$ radiation at $3^{\circ}$ grazing angle and confocal Raman microscope (Alpha 300R, WITec) at an excitation wavelength of $448 \mathrm{~nm}$. Surface morphology of these coatings were studied using a high-resolution scanning electron microscope (HRSEM, Quanta 3D, FEI). Nano-indentation tests were conducted using tribo-indenter (TI 950, HYSITRON) with a Berkovich tip of total included angle $(2 \mathrm{a})=130.5^{\circ}$, radius of curvature $\sim 150 \mathrm{~nm}$ and at a $10 \mathrm{mN}$ trapezoidal load cycle. The values of hardness $(H)$ were calculated from the load-displacement data. The values of elastic modulus $(E)$ were calculated using Oliver and Pharr mathematical procedure. Friction characteristics were carried out using a ballon-disc type linear reciprocating micro-tribometer (CSM Instruments, Switzerland) under dry sliding conditions. Alumina $\left(\mathrm{Al}_{2} \mathrm{O}_{3}\right)$ ball of size $6 \mathrm{~mm}$ was used as sliding ball, applying at three different normal loads of 1,5 and $10 \mathrm{~N}$. A sliding speed of $8 \mathrm{~cm} \mathrm{~s}^{-1}$, frequency of $2 \mathrm{~Hz}$ and a friction stroke length of $5 \mathrm{~mm}$ were used for the total duration of $20 \mathrm{~min}$. The detailed experimental conditions are shown in table 1.

\section{HFCVD process}

For the deposition of diamond films, hot filament CVD system (Model 650 series, $\mathrm{sp}_{3}$ Diamond Technology) with excellent process control system was used, with growth rate of $1 \mu \mathrm{mh}^{-1}$. Deposition parameters such as methane concentration and chamber pressure were controlled easily during the experiment by using throttle valve and mass flow controllers, respectively. Hydrogen $\left(\mathrm{H}_{2}\right)$ and methane $\left(\mathrm{CH}_{4}\right)$ were used as the precursor gases and their flow rates were

Table 2. Growth parameters for the deposition of MCD, NCD and BDNCD coating layers.

\begin{tabular}{lcccccc}
\hline Coating & $\begin{array}{c}\text { Process } \\
\text { pressure (Torr) }\end{array}$ & $\begin{array}{c}\mathrm{CH}_{4} / \mathrm{H}_{2} \\
\text { ratio }(\%)\end{array}$ & $\begin{array}{c}\text { Filament } \\
\text { temperature }\left({ }^{\circ} \mathrm{C}\right)\end{array}$ & $\begin{array}{c}\text { Substrate } \\
\text { temperature }\left({ }^{\circ} \mathrm{C}\right)\end{array}$ & $\begin{array}{c}\text { Boron } \\
\text { concentration }(\%)\end{array}$ & Duration (h) \\
\hline MCD & 36 & 2 & 2200 & $800-850$ & - & 1 \\
NCD & 12 & 4 & 2200 & $800-850$ & - & 1 \\
BDNCD & 12 & 4 & 2200 & $800-850$ & 0.35 & 1 \\
\hline
\end{tabular}

Table 3. Conditions for the two type of samples.

\begin{tabular}{lcccc}
\hline Coating & $\begin{array}{c}\text { Filament } \\
\text { temperature }\left({ }^{\circ} \mathrm{C}\right)\end{array}$ & $\begin{array}{c}\text { Substrate } \\
\text { temperature }\left({ }^{\circ} \mathrm{C}\right)\end{array}$ & $\begin{array}{c}\text { Boron } \\
\text { concentration }(\%)\end{array}$ & $\begin{array}{c}\text { Duration } \\
(\mathrm{h})\end{array}$ \\
\hline MCD-TL-NCD & 2200 & $800-850$ & - & 3 \\
MCD-TL-BDNCD & 2200 & $800-850$ & 0.35 & 3 \\
\hline
\end{tabular}



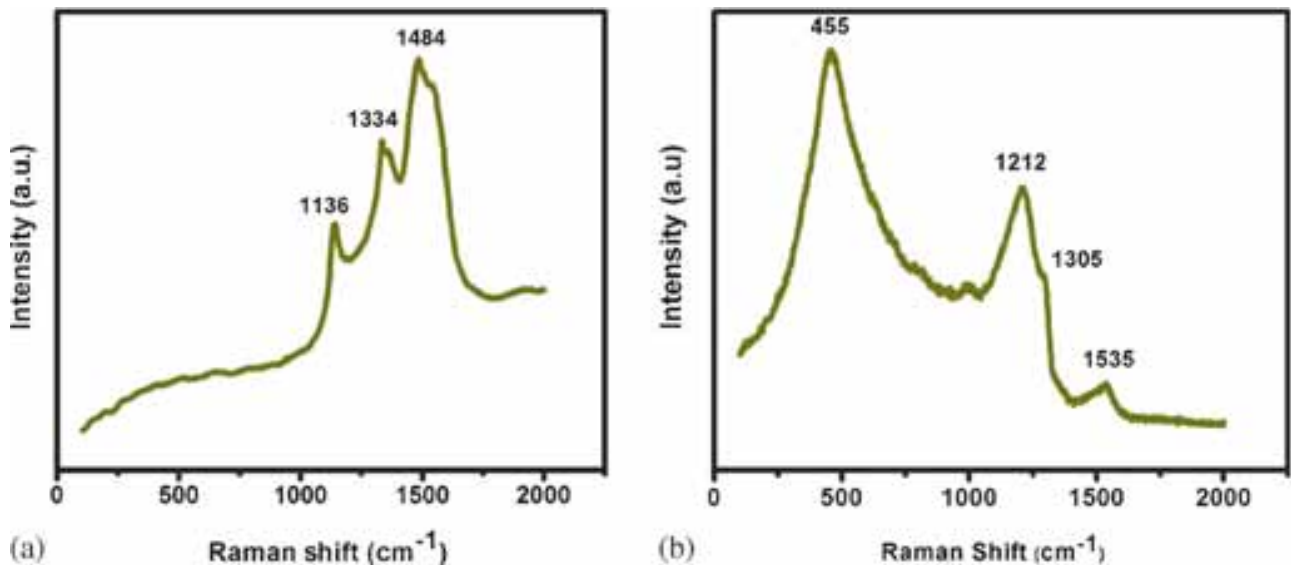

Figure 1. Raman spectra of multilayer CVD-diamond coatings: (a) undoped and (b) boron doped.

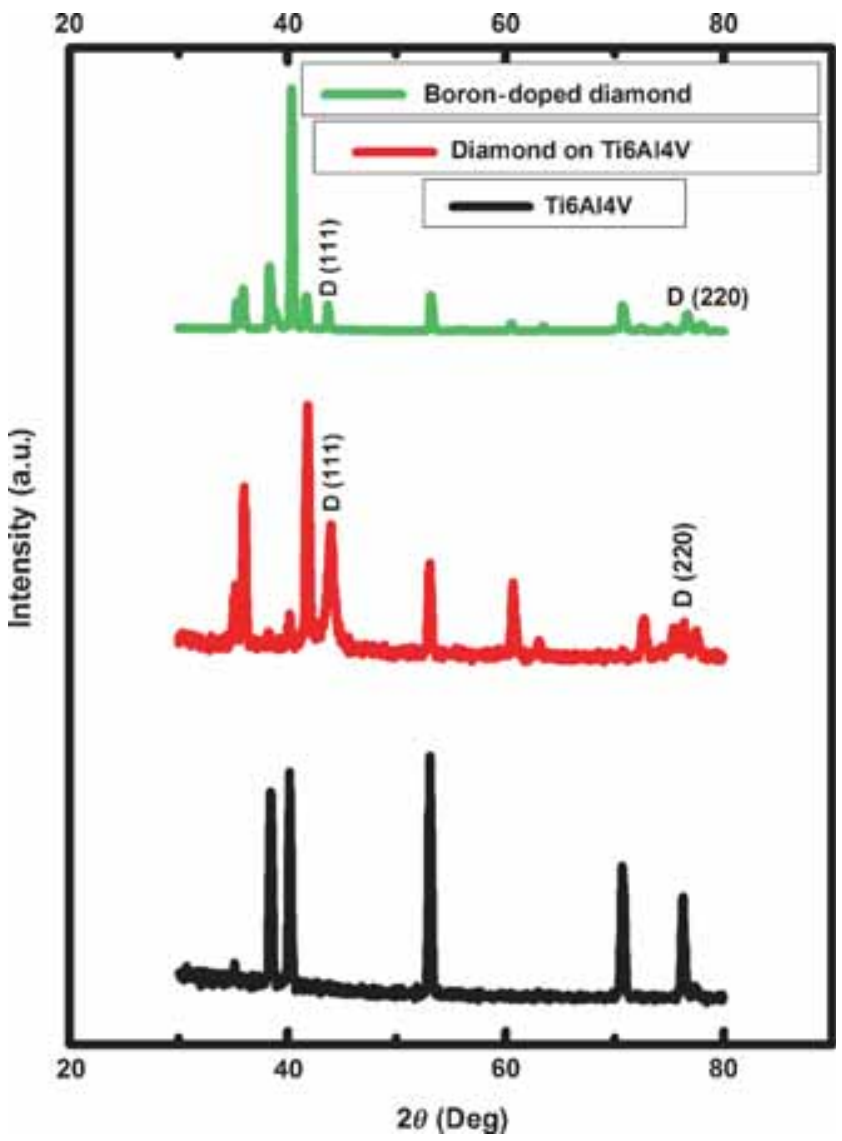

Figure 2. X-ray diffraction patterns of uncoated, multilayer CVD-diamond coatings and boron-doped diamond coatings.

completely controlled using mass flow controllers. An array of tungsten wires $(\varnothing 0.12 \mathrm{~mm}$ ) in systematic order were used as hot filaments for the activation of these precursor gases. The distance between filament and substrate was kept $18 \mathrm{~mm}$ for all the experiments. The grain size of the diamond films were usually controlled by methane concentration and chamber pressure. By decreasing the chamber pressure and increasing the methane concentration, gives the growth of secondary nucleation and therefore decreases the grain size from MCD to that of NCD [28].

In the present work, two types of coating systems were successfully accomplished in order to compare their mechanical and tribological properties, they are: undopedmultilayer CVD-diamond coating system (MCD-TL-NCD) and BD-multilayer CVD-diamond coating system (MCDTLBDNCD). In both cases, coatings were designed by combining the MCD and NCD layers with a transition layer (TL) of $\sim 1 \mu \mathrm{m}$ thickness. This transition layer was actually formed by linearly changing the process parameters from MCD to NCD layer [29]. Whereas, in case of BD multilayer CVDdiamond coating system, a small content of boron $(\sim 0.35 \%)$ was added to the top layer NCD surface, to refine diamond grains, improve film quality and decrease friction coefficient $[18,22]$. The growth parameters for the deposition of MCD, NCD and boron-doped NCD (BDNCD) coatings are listed in table 2. The conditions of two types of samples are given in table 3.

\section{Results and discussions}

In the present work, nano-indentation tests of CVD-diamond coating systems were conducted using Berkovich nanoindenter and the values of hardness were calculated from the load-displacement data. The elastic modulus values were calculated using Oliver and Pharr mathematical method as [28]:

$$
\begin{aligned}
& \text { Hardness }(H)=P / A=P / 24.5 h_{\mathrm{c}}^{2} \text { and } \\
& \operatorname{stiffness}(S)=\mathrm{d} P / \mathrm{d} h=2 E^{*}\left(\frac{\sqrt{A}}{\sqrt{P}}\right) .
\end{aligned}
$$

Elastic modulus $(E)=($ slope of the elastic unloading curve $)$

$$
\times\left(\frac{\sqrt{\pi}}{2 \sqrt{A}}\right) \text {. }
$$


Reduced modulus, $1 / E^{*}=1-v^{2} / E+1-\dot{v}^{2} / E$ $E^{*}=\mathrm{d} P / \mathrm{d} h\left(1 / 2 h_{\mathrm{c}}\right)(1 / \beta)[\sqrt{ } \pi / 24.5]$

$A=3\left(\sqrt{ } 3 h_{\mathrm{c}}^{2}\right) \tan ^{2}(65.3)=24.5 h_{\mathrm{c}}^{2}$ and

$\beta=1.034$ for Berkovich indenter, where $P$ is maximum load, $A$ the area of contact, $h_{\mathrm{c}}$ the contact depth, $E$ modulus of specimen and $E$ modulus of indenter.

Also, the frictional characteristics of these CVD-diamond coating systems were studied using ball-on-disc type linear reciprocating micro-tribometer, sliding against smooth

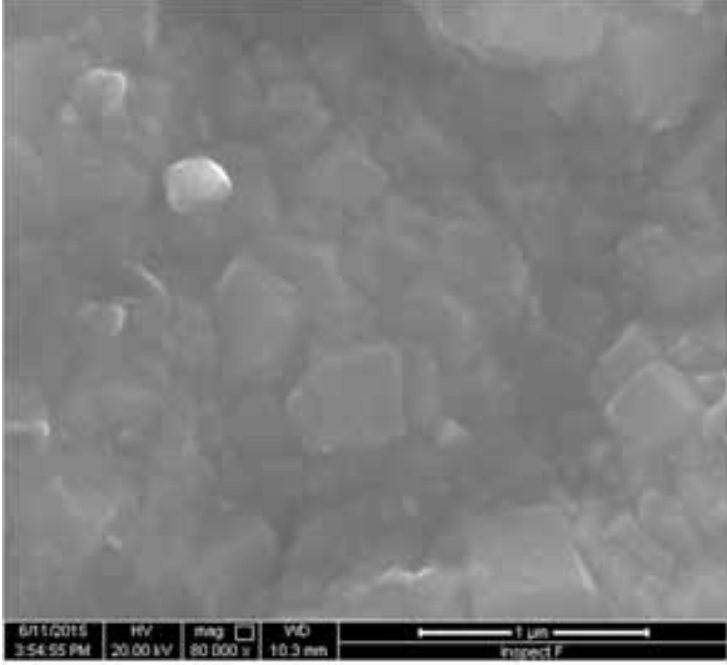

(a)

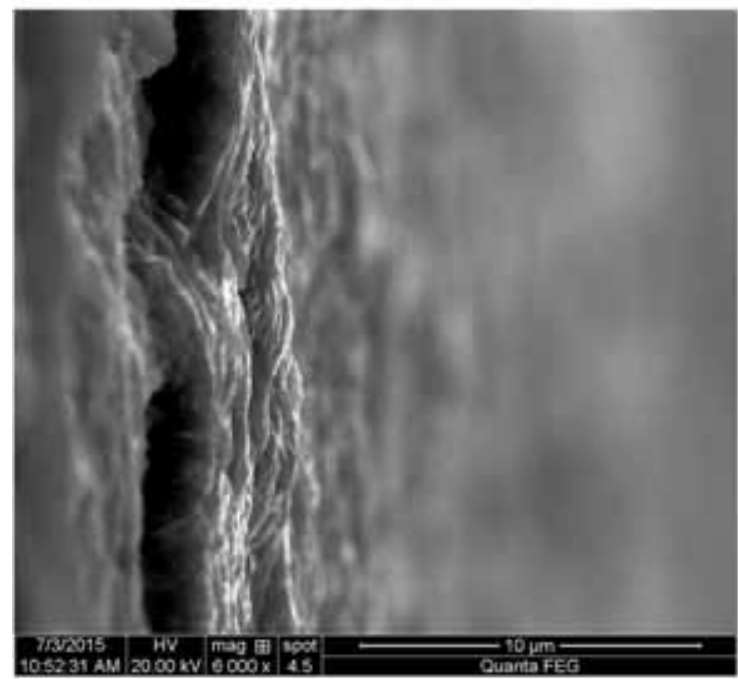

(c)

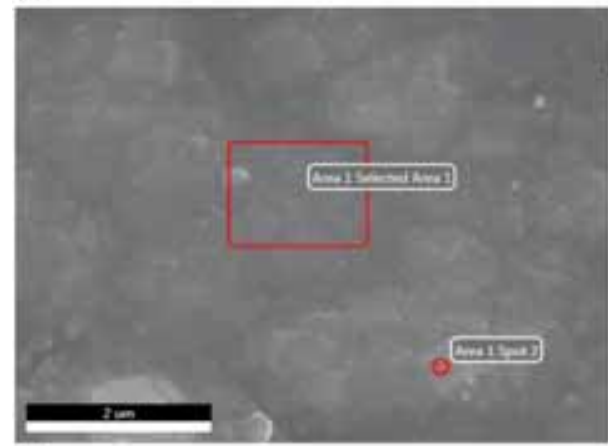

(e)

(f)

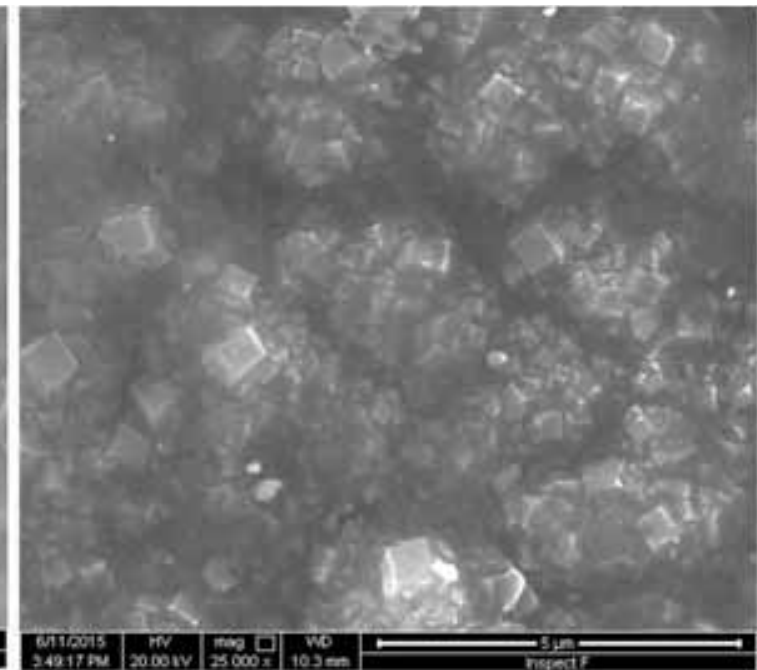

(b)

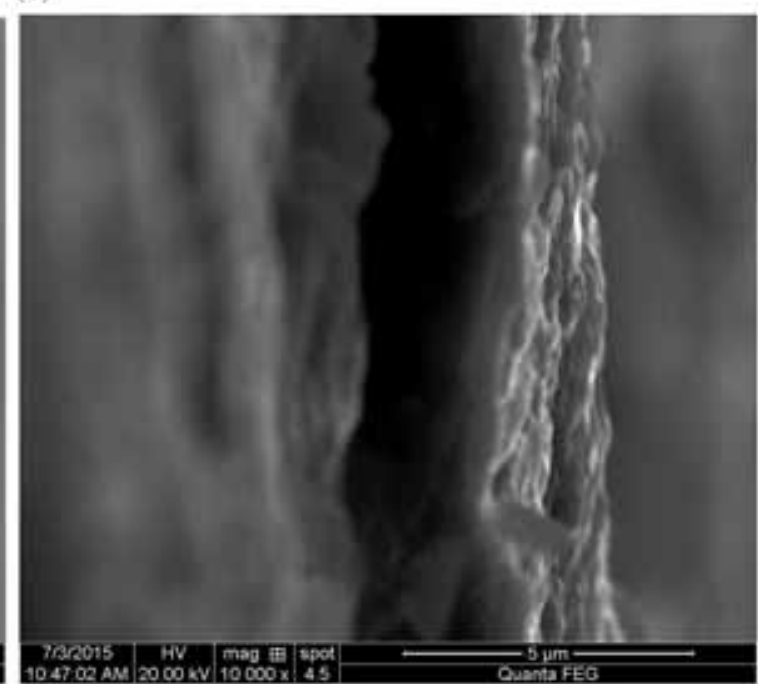

(d)

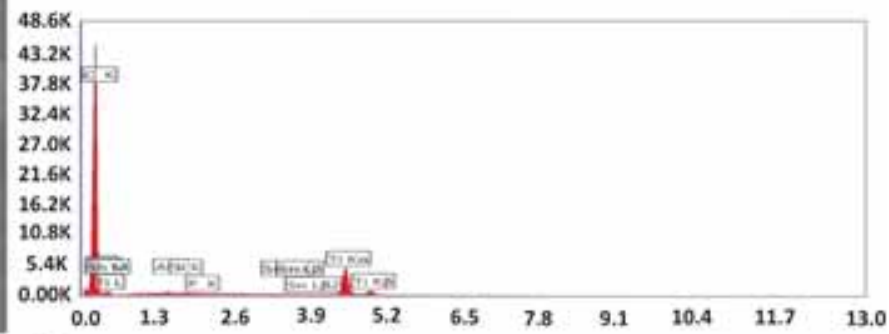

Figure 3. Surface morphologies of (a) undoped coatings and (b) boron-doped diamond coatings. Cross-sectional images of (c) undoped coating and (d) boron-doped diamond coating. (e, f) Energy dispersive X-ray analysis (EDXA) of undoped diamond coatings. (g) Element wise compositions and \% atomic weight of undoped multilayer CVD-diamond coating system. (h) EDXA of boron-doped diamond coatings. (i) element wise composition and \% atomic weight of boron-doped multilayer CVD-diamond coating system. 


\begin{tabular}{|l|l|l|l|l|}
\hline Element & $\begin{array}{l}\text { Weight } \\
\%\end{array}$ & $\begin{array}{l}\text { Atomic } \\
\%\end{array}$ & Net int. & $\begin{array}{l}\text { Net int. } \\
\text { error }\end{array}$ \\
\hline CK & 84.68 & 95.61 & 9522.93 & 0 \\
\hline AIK & 0.27 & 0.14 & 128.33 & 0.03 \\
\hline TiK & 14.38 & 4.07 & 3720.34 & 0 \\
\hline VK & 0.67 & 0.18 & 140.86 & 0.06 \\
\hline
\end{tabular}

(g)

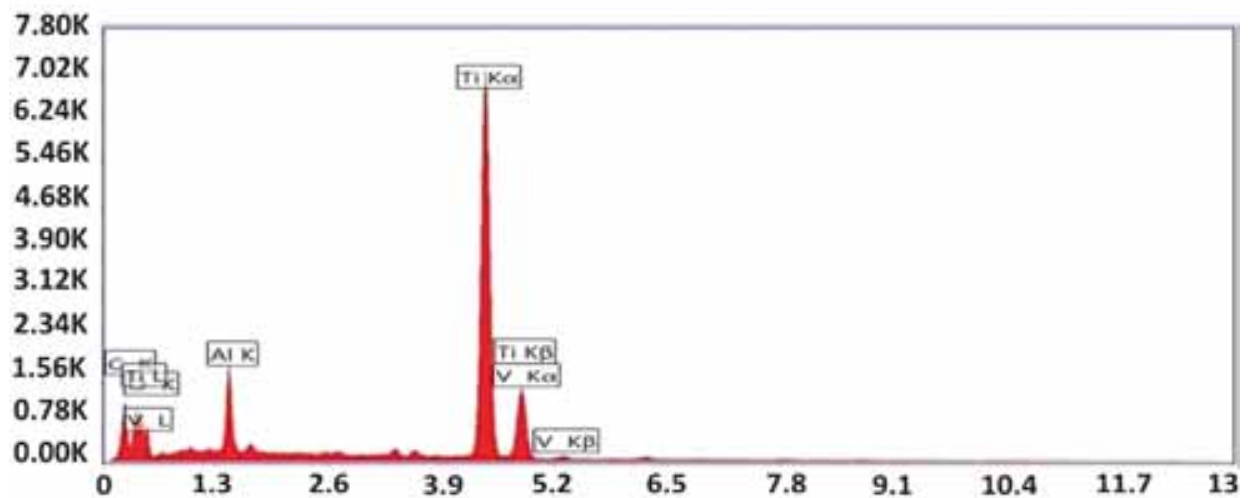

(h)

\begin{tabular}{|l|l|l|l|l|}
\hline Element & $\begin{array}{l}\text { Weight } \\
\%\end{array}$ & $\begin{array}{l}\text { Atomic } \\
\%\end{array}$ & Net int. & $\begin{array}{l}\text { Net int. } \\
\text { error }\end{array}$ \\
\hline CK & 24.54 & 47.22 & 280.33 & 0.01 \\
\hline OK & 15.05 & 21.74 & 95.32 & 0.03 \\
\hline AIK & 5.36 & 4.59 & 412.54 & 0.01 \\
\hline TiK & 51.28 & 24.74 & 2821.45 & 0 \\
\hline VK & 3.77 & 1.71 & 168.57 & 0.04 \\
\hline
\end{tabular}

Figure 3. (Continued)

alumina $\left(\mathrm{Al}_{2} \mathrm{O}_{3}\right)$ ball, with increasing normal load under dry sliding conditions. Experiments were conducted at normal loads of 1,5 and $10 \mathrm{~N}$, sliding velocity $8 \mathrm{~cm} \mathrm{~s}^{-1}$, stroke length
$5 \mathrm{~mm}$, frequency $=2 \mathrm{~Hz}$, temperature $30 \pm 1^{\circ} \mathrm{C}$, duration of rubbing $20 \mathrm{~min}$ and relative humidity $\sim 60 \%$ under ambient atmospheric test conditions. 


\subsection{Raman spectroscopy and residual stress analysis}

Raman spectroscopy is a non-destructive and powerful technique to evaluate the quality of the diamond coatings (presence of non-diamond carbon phases). Raman spectroscopy was used to check the chemical structure and crystallinity of the diamond coatings and if the crystalline diamond coating shows a fundamental Raman peak at $\sim 1333 \mathrm{~cm}^{-1}$, it confirms that the coating is diamond in nature [30]. Figure 1a and b shows the Raman spectra of undoped and BD multilayerdiamond coating systems, respectively. In figure $1 \mathrm{a}$, the characteristic fundamental Raman peak of undoped multilayer-diamond coating system exists at $1334 \mathrm{~cm}^{-1}$ and this shift of fundamental Raman peak towards higher side of $1333 \mathrm{~cm}^{-1}$ shows that the residual compressive stresses are present. Mainly, these residual compressive stresses exist due to the difference in thermal expansion coefficients between substrate and coating [31-33]. Residual stresses can be calculated as $-0.348\left(v_{\mathrm{m}}-v_{0}\right) \mathrm{GPa}$ for fundamental Raman peak at $v_{\mathrm{m}}$, where $v_{0}=1332 \mathrm{~cm}^{-1}$ and $v_{\mathrm{m}}=1334 \mathrm{~cm}^{-1}$ [26]. Thus, undoped multilayer-diamond coating system contains a compressive stress of $-0.696 \mathrm{GPa}$, where negative sign indicates compressive stress. Two other peaks $v_{1}=1136 \mathrm{~cm}^{-1}$ and $\nu_{3}=1484 \mathrm{~cm}^{-1}$ are characteristics of in-plane $(\mathrm{C}-\mathrm{H})$ and stretching $(\mathrm{C}=\mathrm{C})$ vibrational modes, respectively. The existence of these modes was ascribed to the formation of trans-polyacetylene chain in the grain boundaries in case of NCD coating [27]. For BD multilayerdiamond coating system, the characteristic fundamental Raman peak at $1336 \mathrm{~cm}^{-1}$ shifts to lower value at $1305 \mathrm{~cm}^{-1}$ due to slight boron doping, and the peak at $1535 \mathrm{~cm}^{-1}$ shows the presence of graphitic carbon phases ( $G$ band). Hence, this downshift of the fundamental Raman peak is due to the fano interaction, the result of the breakdown of the $k=0$ selection rule and also due to boron doping. The two other peaks approximately 455 and $1212 \mathrm{~cm}^{-1}$ represent the actual boron incorporation in the lattice [34]. The residual tensile stresses for the BD multilayer-diamond coating system can be also calculated as: $-0.348(1305-1332)=5.916 \mathrm{GPa}$, where positive sign implies tensile stress.

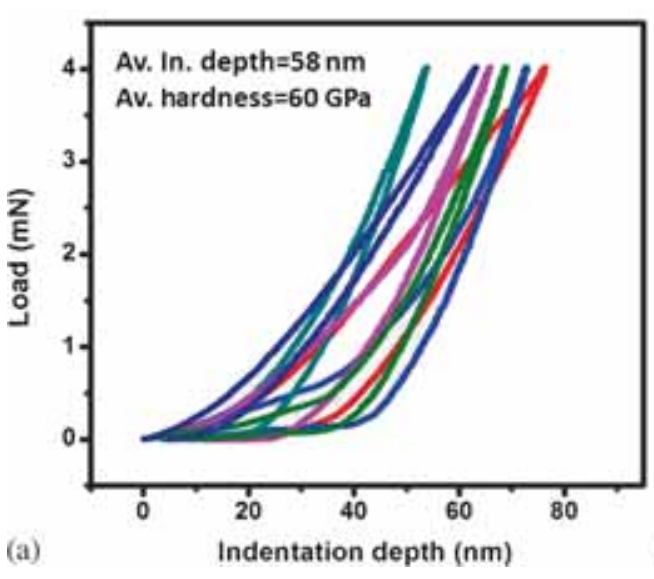

\subsection{XRD technique}

XRD is an excellent technique to identify and study the structural characteristics of the crystalline materials and it offers unmatched accuracy in the quantification of atomic spacing. The XRD patterns of multilayer CVD-diamond coating systems are shown in figure 2. Sharp and strong peaks of cubic diamond coatings were observed at (111) crystal and (220) crystal planes at diffraction angles of $44^{\circ}$ and $75.5^{\circ}$, respectively, for this coating system, along with the substrate peaks. This confirms the crystallinity of the top layer NCD coating. Also the variations in these peaks show that there are different interferences at different planes. The highest peaks of substrate show that its grain size is more than diamond coating. Since, with the addition of boron content the grain size and thus lattice parameter of diamond film may be changed. Therefore, using the equations given by Brunet [35], the change of the lattice constant of the BD NCD film can be presented as:

Vegard's Law gives

$$
\frac{\Delta a}{a}=\frac{r_{\mathrm{B}}-r_{\mathrm{c}}}{r_{\mathrm{c}}[c]}[\mathrm{B}]=\beta[\mathrm{B}],
$$

where, $r_{\mathrm{B}}$ and $r_{\mathrm{c}}$ are cumulative differences between the covalent radii sizes of the doping and the host atoms.

Where, $\Delta a=a-a_{0}, a_{0}=3.5619 \AA$ for undoped diamond film, $a=a_{0}+\Delta_{\mathrm{a}}=\left(3.5619+\Delta_{\mathrm{a}}\right) \AA$ for BDD film and $[\mathrm{B}]=0.35$ is the concentration per unit volume of the boron atom.

$$
\beta\left(\mathrm{cm}^{3}\right)=\left[3.87 \times 10^{-25}+3.73 \times 10^{-45}\right][0.35]
$$

and from equation (i),

$$
\begin{aligned}
& \frac{\Delta a}{a}=3.87 \times 10^{-25}[0.35] \\
& \frac{\Delta a}{a}=1.35 \times 10^{-25} .
\end{aligned}
$$

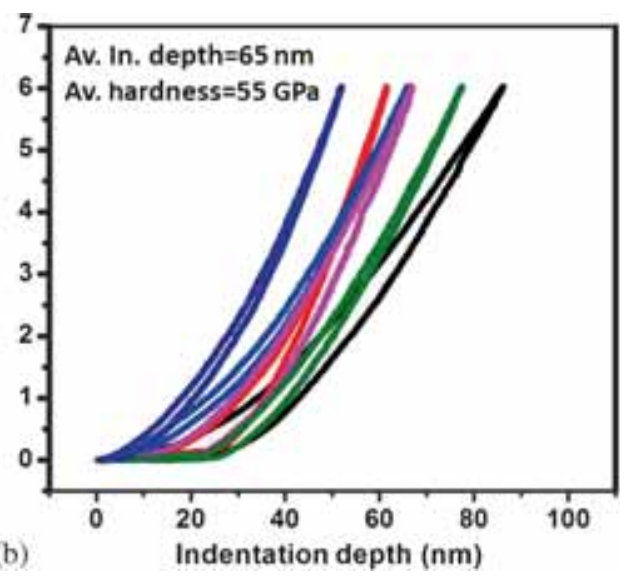

Figure 4. Load-displacement curves corresponding to six indentations on multilayer CVD-diamond coatings: (a) undoped and (b) boron-doped. 


\subsection{Scanning electron microscopy technique}

The scanning electron microscopy (SEM) was used to study the morphology and grain size of diamond films. With the increase in methane concentration, secondary nucleation takes place which changes the nature of existing grains from microcrystalline to nanocrystalline. Therefore, a cauliflower type of morphology is generally shown by the top-layer (NCD) of multilayer CVD diamond coatings [36]. Figure 3a shows the general surface morphology of the top-layer (undoped-NCD) of the multilayer CVD-diamond coating system, whereas figure $3 \mathrm{~b}$ shows the surface morphology of the top layer of BDD coatings. Figure $3 \mathrm{c}$ shows the cross-sectional view of the undoped diamond coatings and figure $3 \mathrm{~d}$ shows the cross-sectional view of the BDD coatings. The element wise composition and \% atomic weight of undoped multilayer CVD-diamond coating system are also shown in EDXA diagram, in figure $3 \mathrm{e}-\mathrm{g}$. The element wise composition and \% atomic weight of boron doped multilayer CVD-diamond coating system are also shown in EDXA diagram, in figure $3 \mathrm{~h}$ and $\mathrm{i}$.

\subsection{Hardness and friction measurement}

The best method to determine the hardness of materials is nano-indentation. Figure $4 \mathrm{a}$ and $\mathrm{b}$ shows the load-displacement curves corresponding to six indentations carried out on undoped and BD-multilayer CVD-diamond coating systems, respectively. The average indentation depth for undoped-multilayer diamond coating system was $\sim 58 \mathrm{~nm}$, whereas for BD-multilayer diamond coating system, it was $\sim 65 \mathrm{~nm}$. Hardness values of undoped-multilayer diamond coating system were in the range $60 \mathrm{GPa}$ and these values approximately resemble the recent research work done on CVD-diamond coatings [24]. Whereas, the hardness values of BD-multilayer diamond coating system has slightly decreased and is in the range of $55 \mathrm{GPa}$.

Friction is the resistance to motion which is experienced when one body moves tangentially over another body with which it is in contact. Frictional characteristics of the CVDdiamond coatings were studied, when sliding against smooth alumina $\left(\mathrm{Al}_{2} \mathrm{O}_{3}\right)$ balls, using ball-on-disc micro-tribometer with increasing normal load and for the duration of $20 \mathrm{~min}$. Figure 5d shows the variation of average friction coefficient of undoped-multilayer diamond coating system with the increasing load from 1 to $10 \mathrm{~N}$, whereas figure $5 \mathrm{a}-\mathrm{c}$ show the variation of friction coefficient with the duration of rubbing at 1,5 and $10 \mathrm{~N}$ loads, respectively. The average frictional coefficient of undoped-multilayer diamond coating system decreases from 0.36 to 0.29 by increasing the normal load from 1 to 10 N. Figure $6 d$ shows the variation of average friction coefficient of BD-multilayer diamond coating
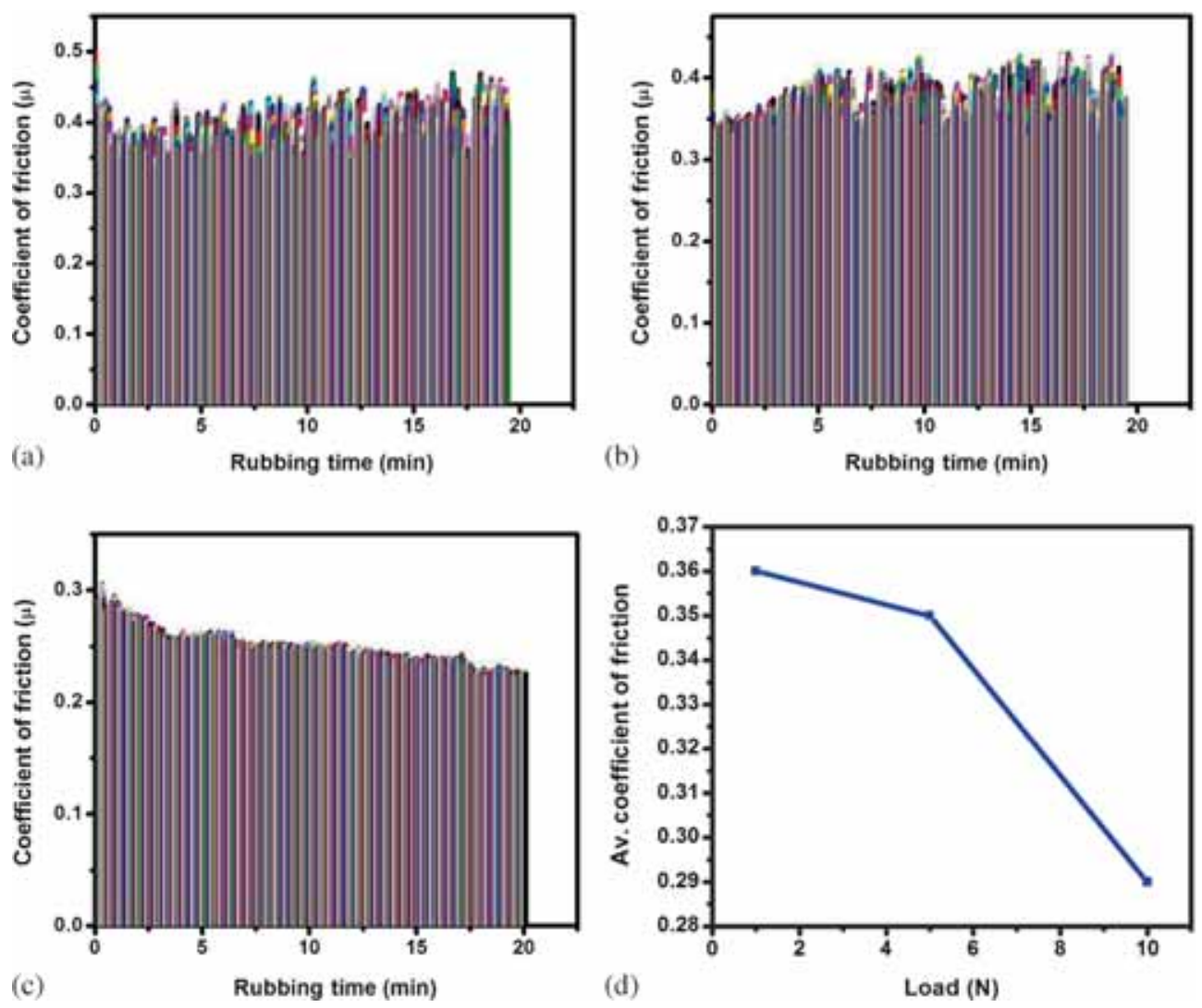

Figure 5. Variation of friction coefficient of undoped multilayer-diamond coatings, sliding against $\mathrm{Al}_{2} \mathrm{O}_{3}$ ball with respect to (a) normal load and duration of rubbing at (a) 1 , (b) 5 and (c) $10 \mathrm{~N}$ loads. (d) Average coefficient of friction and normal load. 

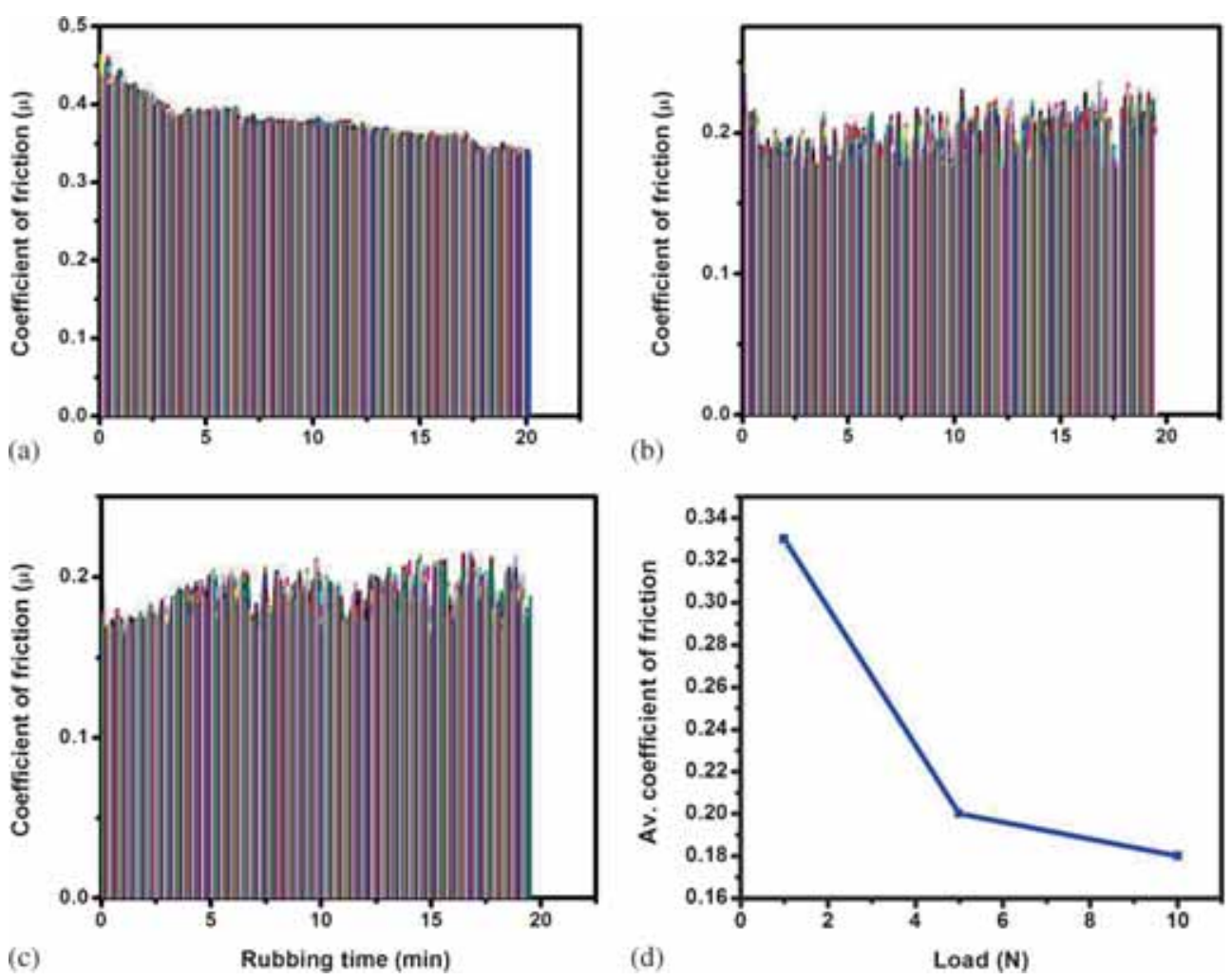

Figure 6. Variation of friction coefficient of doped multilayer-diamond coatings, sliding against $\mathrm{Al}_{2} \mathrm{O}_{3}$ ball with respect to normal load and duration of rubbing at (a) 1 , (b) 5 and (c) $10 \mathrm{~N}$ loads. (d) Average coefficient of friction and normal load.

Table 4. Experimental mechanical and tribological results.

\begin{tabular}{|c|c|c|c|c|c|c|c|}
\hline Coating type & $\begin{array}{c}\text { Residual } \\
\text { stresses }(\sigma)\end{array}$ & $\begin{array}{l}\text { Indentation } \\
\text { depth }(h)\end{array}$ & $\begin{array}{c}\text { Hardness } \\
\text { values }(H)\end{array}$ & $\begin{array}{c}\text { Elastic } \\
\text { modulus }(E)\end{array}$ & $\begin{array}{l}\text { Variation in } \\
\text { friction coefficient }\end{array}$ & $\begin{array}{l}\text { Decrease in } \\
\% \text { hardness }\end{array}$ & $\begin{array}{c}\text { Decrease in } \\
\% \text { elastic modulus }\end{array}$ \\
\hline MCD-TL-NCD & $-0.696 \mathrm{GPa}$ & $\sim 58 \mathrm{~nm}$ & $\sim 60 \mathrm{GPa}$ & $\sim 1100 \mathrm{GPa}$ & $0.36-0.29$ & & \\
\hline MCD-TL-BDNCD & $5.916 \mathrm{GPa}$ & $\sim 65 \mathrm{~nm}$ & $\sim 55 \mathrm{GPa}$ & $\sim 1050 \mathrm{GPa}$ & $0.33-0.18$ & 8.33 & 4.54 \\
\hline
\end{tabular}

system with the increasing load from 1 to $10 \mathrm{~N}$, whereas figure $6 a-c$ show the variation of friction coefficient with the duration of rubbing at 1,5 and $10 \mathrm{~N}$ loads, respectively. Similarly, the average frictional coefficient of BD-multilayer diamond coating system decreases from 0.33 to 0.18 , by increasing the normal load from 1 to $10 \mathrm{~N}$. These CVDdiamond coating systems undergo phase transformation during long-duration of rubbing, high-load (high-speed) sliding tests and then the transformation products trapped at the sliding interfaces, can periodically influence the friction and wear performance [37]. The detailed mechanical and tribological experimental results are shown in table 4 . It can be concluded that the average coefficient of friction decreases from 0.36 to 0.29 (undoped diamond coating) and from 0.33 to 0.18 (boron-doped diamond coating).

In CVD diamond layer the boron incorporation between diamond grains would reduce the purity and quality of diamond thin films to some extent, resulting in lower hardness and Young's modulus of BDD film compared with un-doped diamond film $[38,39]$. The friction coefficient of B-doped diamond films is lower than that of the undoped diamond films although the B-doped diamond films present larger crystallites and rougher surface. The boron carbide chemical bonds may exist in the B-doped diamond films; it would help change the surface frictional energy dissipation and thus change the COF. The oxide generated by friction may serve as solid lubrication, which will help to decrease $\mathrm{COF}$ for B-doped diamond films [34]. The lower friction coefficient of BDD films is due to the interaction mechanism between two contacting surfaces being changed because of boron incorporation. The boron carbide chemical bonds may exist in the BDD films; it would help change the surface frictional energy dissipation and thus change the coefficient of friction. 


\section{Conclusion}

The effect of boron doping on lattice parameters, residual stresses, hardness and frictional coefficient of multilayerdiamond coating system were analysed. It was revealed that boron doping increases grain size (or lattice parameter), refines crystal lattice and improves formation of the diamond phase in the films as confirmed by Raman spectroscopy. At low boron concentration, the fundamental characteristic diamond peak at $1336 \mathrm{~cm}^{-1}$ downshift to $1305 \mathrm{~cm}^{-1}$, the compressive residual stresses were changed to tensile stresses and the hardness of multilayer CVD-diamond-coated Ti6Al4V substrates was slightly decreased. It was observed that with increase in normal load the BD multilayer diamond coating systems show less average coefficient of friction than the undoped ones. Furthermore, it was also observed that the coefficient of friction for both undoped and doped diamond coating systems becomes steady after certain duration of rubbing and this was attributed to the presence of graphitic carbon phases at the grain boundaries of the top layer NCD film. Therefore, depositing smooth, adhesive and thick BD multilayer diamond coating system on Ti6Al4V substrates enhances its tribological properties.

\section{Acknowledgements}

We would like to thank MSRC lab, IIT Madras, for the deposition of coatings and C. Anandan (Surface Engineering Division, NAL, Bangalore, India) for doing tribological tests. Sajad Hussain is thankful to Dinesh Kumar (Physics Department, IIT Madras), Ravi Kumar Dumpala, Mohammad Jebran Khan, M. Sidiq and Aashiq Hussain Sofi (Physics Department, NIT Srinagar) for their good assistance during the experimental work.

\section{References}

[1] Liu Y K, Tzeng Y, Liu C, Tso P and Lin I N 2004 Diamond Relat. Mater. 1859

[2] Chavanne A, Arnault J C, Barjon J and Arabski J 2011 Surf. Sci. 605564

[3] Tang C J, Fernandes A J S, Girao A V, Pereira S, Shi F N, Soares M R et al 2014 J. Cryst. Growth 38983

[4] Saito D, Isshiki H and Kimura T 2009 Diamond Relat. Mater. 1856

[5] Weng J, Wang J H, Dai S Y, Xiong L W, Man W D and Liu F 2013 Appl. Surface Sci. 276529

[6] Tang C J, Pereira S M S, Fernandes A J S, Neves A J, Gracio J, Bdikin I K et al 2009 J. Cryst. Growth 3112258

[7] Wang X, Zhang J, Shen B, Zhang T and Sun F 2014 Wear 3121

[8] Migliorini F L, Alegre M D, Baldan M R, Lanza M R V and Farreira N G 2014 Thin Solid Films 56497

[9] Dauskardt R H, Lane M, Ma Q and Krishna N 1998 Eng. Fract. Mech. 61141

[10] Booth L, Catledge S A, Nolen D, Thompson R G and Vohra Y K 2011 Materials 4857
[11] Zhang J, Wang X, Shen B and Sun F 2013 Int. J. Refract. Met. Hard Mater. 41285

[12] Catledge S A, Borham J, Vohra Y K, Lacefield W R and Lemons J E 2002 J. Appl. Phys. 915347

[13] Jiang N, Sugimoto K, Nishimura K, Shintani Y and Hiraki A 2002 J. Cryst. Growth 242362

[14] Takeuchi S, Oda S and Murakawa M 2001 Thin Solid Films 398-399 238

[15] Schafer L, Höfer M and Kröger R 2006 Thin Solid Films 515 1017

[16] Lia Almeida A, Salgueiredo E, Filipe Oliveira J, Rui Silva F, Daniel Baptista L, Suzana Peripolli B and Carlos Achete A 2013 ACS Appl. Mater. Interfaces 511725

[17] Neto M A, Silva E L, Ghumman C A, Teodoro O M, Fernandes A J S, Oleiveira F J and Silva R F 2012 Thin Solid Films 5205260

[18] Wang L, Lei X, Shen B, Sun F and Zhang Z 2013 Diamond Relat. Mater. 3354

[19] Salgueiredo E, Abreu C S, Amaral M, Oliveira F J, Gomes J R and Silva R F 2013 Wear 303225

[20] Wang J, Zhou J, Long H Y, Xie Y N, Zhang X W, Luo H et al 2014 Surf. Coat. Tech. 2581032

[21] Abu Suilik S B, Ohshima M, Tetsui T and Hasezaki K 2008 Vacuum $\mathbf{8 2} 1325$

[22] Liu Z, Xu F, Xu J, Tang X, Liu Y and Zuo D 2015 Int. J. Chem. Nucl. Mater. Metall. Eng. 9632

[23] Salgueiredo S, Almeida F A, Amaral M, Neto M A, Oliveira F J and Silva R F 2013 Wear 2971064

[24] Lu F X, He Q, Gao S B, Zhang F L and Tong Y M 2010 Diamond Relat. Mater. 19936

[25] Zhang D C, Shen B and Sun F H 2010 Appl. Surf. Sci. 256 2479

[26] Kromaka A, Davydova M, Rezek B, Vanecek M, Stuchlik M, Exnar P and Kalbac M 2010 Diamond Relat. Mater. 19 196

[27] Oliver W C and Pharr G M 1992 J. Mater. Res. 71564

[28] Ali M and Ürgen M 2011 Appl. Surf. Sci. 2578420

[29] Dumpala R, Chandran M, Kumar N, Dash S, Ramamoorthy B and Ramachandra Rao M S 2013 Int. J. Refract. Met. Hard Mater. 37127

[30] Prawer S and Nemanich R J 2004 Philos. Trans. Royal Soc. London A 3622537

[31] Gunnars J and Alahelisten A 1996 Surf. Coat. Technol. 80 303

[32] Chandran M, Kumaran C R, Gowthama S, Shanmugam P, Natarajan R, Bhattacharya S S and Ramachandra Rao M S 2013 Int. J. Refract. Met. Hard Mater. 37117

[33] Kuzmany H, Pfeiffer R, Salk N and Günther B 2004 Carbon 42911

[34] Liang Q, Stanishevsky A and Yogesh Vohra K 2008 Thin Solid Films $\mathbf{5 1 7} 800$

[35] Brunet F, Deneuville A, Germi P, Pernet M and Gheeraert E 1997 Appl. Phys. Lett. 811120

[36] Kulisch W and Popov C 2006 Physica Status Solidi A 203203

[37] Erdemir A, Fenske G R, Krauss A R, Gruen D M, McCauley T and Csencsits R T 1999 Surf. Coat. Technol. 120565

[38] Yan C, Mao H, Li W, Qian J, Zhao Y and Hemley R J 2004 Physica Status Solidi 201 R25

[39] Li X M, Wang J D, Chen D R, Liu B and Liu F B 2005 J. Chin. Ceram. Soc. 331539 